\title{
Tolerance-Insensitive Design of the Magnet Shape for a Surface Permanent Magnet Synchronous Motor
}

\author{
Chung-Seong Lee ${ }^{1}$, Kyoung-Soo Cha ${ }^{2} \mathbb{D}$, Jin-Cheol Park ${ }^{2}$ and Myung-Seop Lim ${ }^{2, *}$ \\ 1 Central R\&D Center, Mando Corporation, Seongnam 13486, Korea; chungseong.lee@halla.com \\ 2 Department of Automotive Engineering, Graduate School of Engineering, Hanyang University, \\ Seoul 04763, Korea; chakungsoo@hanyang.ac.kr (K.-S.C.); skensk1990@hanyang.ac.kr (J.-C.P.) \\ * Correspondence: myungseop@hanyang.ac.kr
}

Received: 31 January 2020; Accepted: 9 March 2020; Published: 11 March 2020

check for updates

\begin{abstract}
Many studies have been conducted to reduce the cogging torque of electric power steering motors. However, in the mass production of such motors, it is essential to enhance performance robustness in relation to tolerances. For such motors, this work analyzes performance robustness in relation to tolerances by applying a cycloid curve to the surface magnet of the rotor. Applying a cycloid curve to the magnet surface of the rotor is one of several ways to reduce cogging torque. To evaluate the performance of the cycloid curve, we compare it with an eccentric curve. The two curves are compared for the same specifications and evaluated using the indicator, tolerance insensitivity rate, which is used to assess performance robustness in relation to tolerances. The cycloid curve was evaluated to be more robust in relation to tolerances, as compared with the eccentric curve. Finally, an experiment was conducted to validate the robustness of the cycloid curve.
\end{abstract}

Keywords: tolerance insensitivity rate (TIR); surface permanent magnet (SPM) motor; cogging torque; cycloid curve; eccentricity curve; electric power steering (EPS)

\section{Introduction}

Because of environmental pollution, vehicle emission regulations are becoming increasingly tightened; therefore, interest in eco-friendly vehicles, such as electric and hybrid vehicles, that can reduce exhaust gas emissions is also increasing [1]. In such green vehicles, components have been replaced with modern electrical systems that work more efficiently than those in internal combustion engine (ICE) vehicles. In particular, the adoption of motors in the components of ICE vehicles allows for the enhancement of fuel efficiency in driving and chassis systems.

The electric power steering (EPS) system is a motorized chassis system that offers the advantages of efficiency and size over conventional hydraulic power steering systems. These advantages offer significant energy savings for automobiles. However, the motor used in an EPS system can cause issues for the driver (i.e., the cogging torque of the motor deteriorates the driver's "feel" of the steering). Therefore, cogging torque must be reduced in the EPS system.

Reduction of the cogging torque of motors has been studied extensively in various ways. Cogging torque is dependent on geometrical parameters of the motor. For this reason, Levin mentioned the representative methods to reduce cogging torque and introduced the skewing of the stator slot and change of slot opening [2]. The shape design is another method to reduce cogging torque by applying eccentricity to the rotor shape and a notch to the stator shape [3-5]. Blum et al. and Fei et al. reduced cogging torque by applying skew to the rotor [6,7]. Jung et al. improved cogging torque by making the rotor shape cosine with pore flux density [8]. Kim et al. and Coenen et al. analyzed the period and amplitude of the additional cogging torque that occurs when a tolerance occurs in the motor $[9,10]$. 
In past studies, cycloid curves have been widely applied in mechanical fields (e.g., in speed reducers and oil pumps) [11,12]. However, in the study by Park, Lim, and Lee [13], the cycloid curve was applied to the rotor of a motor. In their study, it was also verified that cogging torque was improved for a motor to which a cycloid curve was applied. However, the presence of tolerances in the cycloid curve was not analyzed. Such tolerances inevitably occur in motor mass production and can also generate additional, unexpected cogging torque; therefore, it is necessary to analyze these tolerances to reduce cogging torque [14-17].

In this study, we analyze the effects of the tolerances of cycloid curves applied to an EPS motor. First, the definition and shape of the cycloid curve are explained. The shapes of the cycloid and the general eccentricity curve are compared according to $\delta q$. The term $\delta q$ is an index that determines the shape of a rotor; it is defined as the distance between the rotor radius and the point of intersection where the rotor magnet contacts the q-axis. Second, the effects of cogging torque on the tolerances in cycloid and eccentricity curves are analyzed. The tolerance of each curve is the change in $\delta q$. In addition, the tolerance insensitivity rate (TIR) is applied to analyze the sensitivity of the cogging torque according to the tolerance. The TIR is an indicator of the effect of tolerances as a percentage of the motor's performance change in the presence of such tolerances. Third, we analyze a case in which the same tolerance occurs in cycloid and eccentric rotor shapes. Finally, the validity of the work is verified through experiments using cycloid and eccentric motors.

\section{Cycloid Curve}

\subsection{Definition and Type}

A cycloid curve is the trajectory drawn by a fixed point on a rolling wheel when the rolling circle rolls in a straight line. Table 1 summarizes the types of cycloid curves. Cycloids can be divided into two types depending on whether the rolling wheel rolls in a straight line or a fixed circle.

Table 1. Cycloid curve types.

Location of the Point
On the Circumference
$\begin{gathered}\text { Circle rolls in a straight } \\ \text { line }\end{gathered}$
Circle rolls outside a
fixed circle

A cycloid is defined as the curve generated when the trajectory is drawn by a fixed point located at the outermost edge of the rolling circle. The curve generated when the fixed point drawing the trajectory is located inside or outside of the circumference is defined as trochoid. The cycloid on the fixed circle is termed an epicycloid curve when the fixed point that draws the trajectory of the rolling circle is at the outermost edge of the rolling circle. When the fixed point that draws trajectories on the rolling wheel exists inside or outside the rolling wheel, it is termed epitrochoid. A curtate epitrochoid 
(CET) occurs when the fixed point that draws trajectories on the rolling circle is inside the rolling circle, whereas prolate epitrochoid (PET) curves occur when it is outside the rolling circle.

Because this study deals with rotating machines, the performance of the motor was analyzed by applying the trajectory of the cycloid generated on a circle, rather than on a straight line, to the rotor surface shape.

\subsection{Curve Formula and Selection}

Of the various types of cycloid curves (Table 1), the applicable curves for the magnet shape are epicycloid, curtate epitrochoid (CET), and prolate epitrochoid (PET). In this chapter, these three types of cycloid trajectories occurring on fixed circles are presented as mathematical models.

\subsubsection{Epicycloid}

Figure 1 shows the epicycloid curve that is the basis of the CET and PET curves. $R_{r}$ is the radius of the rolling wheel; $R_{f}$ is the radius of the fixed circle; and $O$ is the center of the fixed circle. When drawing the trajectory based on a fixed point of the rolling wheel located at the outermost edge, the geometric shape generated by the red line becomes an epicycloid curve.

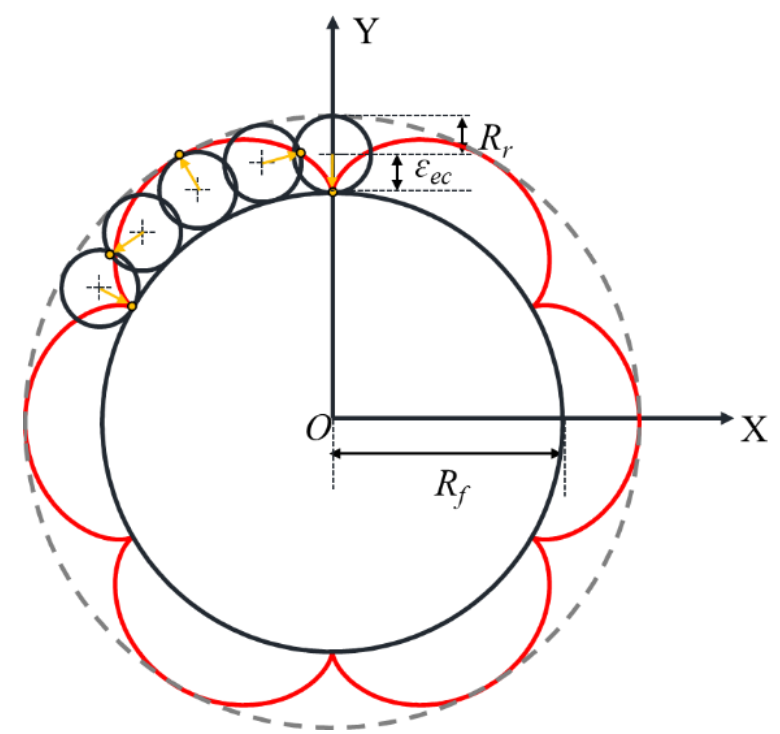

Figure 1. Epicycloid curve.

$\varepsilon_{e c}$ is an indicator that determines the curve type (i.e., epicycloid, CET, or PET). $\varepsilon_{e c}$ is the position of the point that draws the trajectory. Therefore, if $\varepsilon_{e c}$ equals $R_{r c}$, as shown in (1), the epicycloid curve is drawn because the fixed point for the trajectory is located at the outermost edge of the rolling wheel.

$$
\varepsilon_{e c}=R_{r}
$$

$n$ is the number of curves in which the cycloid curve occurs above the fixed circle. The determination condition of $\mathrm{n}$ is represented by (2), where $n$ is an integer of 1 or more

$$
n=\frac{R_{f c}}{R_{r c}}
$$


When the epicycloid trajectory is expressed in rectangular coordinates, (3) is used. $x_{e c}$ indicates $\mathrm{x}$-axis coordinates in rectangular coordinates and $y_{e c}$ indicates $\mathrm{y}$-axis coordinates in rectangular coordinates.

$$
\left\{\begin{array}{l}
x_{e c}=\left(R_{f}+R_{r}\right) \cos \theta-\varepsilon_{e c} \cos ((n+1) \theta) \\
y_{e c}=\left(R_{f}+R_{r}\right) \sin \theta-\varepsilon_{e c} \sin ((n+1) \theta)
\end{array}\right.
$$

\subsubsection{Curtate Epitrochoid}

Figure 2 shows the CET curve. The trajectory of CET is determined by (4). The fixed point drawing the trajectory is located inside the rolling wheel. If the trajectory is displayed according to the rolling position, it follows the blue line.

$$
\varepsilon_{c e t}<R_{r}
$$

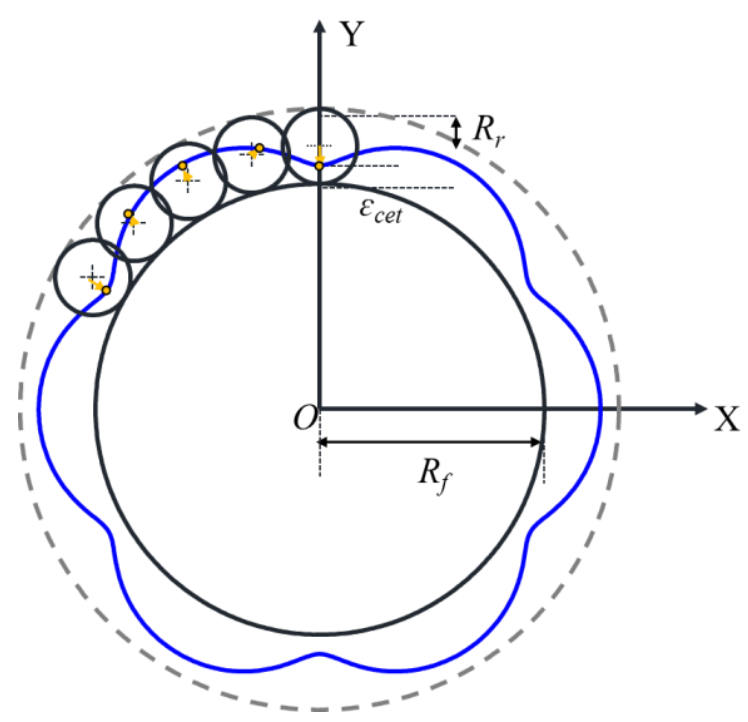

Figure 2. Curtate epitrochoid (CET) curve.

When the CET curve is expressed by rectangular coordinates, it is the same as that of (5).

$$
\left\{\begin{array}{l}
x_{c e t}=\left(R_{f}+R_{r}\right) \cos \theta-\varepsilon_{c e t} \cos ((n+1) \theta) \\
y_{c e t}=\left(R_{f}+R_{r}\right) \sin \theta-\varepsilon_{c e t} \sin ((n+1) \theta)
\end{array}\right.
$$

Figure 3 shows the PET curve. The PET trajectory is determined by (6). The point that draws the trajectory is located outside the rolling circle. If the trajectory is displayed according to the rolling position, it follows the green line.

$$
\varepsilon_{\text {pet }}>R_{r}
$$

\subsubsection{Prolate Epitrochoid}

When the PET curve is expressed by rectangular coordinates, it is the same as that of (7).

$$
\left\{\begin{array}{l}
x_{\text {pet }}=\left(R_{f}+R_{r}\right) \cos \theta-\varepsilon_{\text {pet }} \cos ((n+1) \theta) \\
y_{\text {pet }}=\left(R_{f}+R_{r}\right) \sin \theta-\varepsilon_{\text {pet }} \sin ((n+1) \theta)
\end{array}\right.
$$




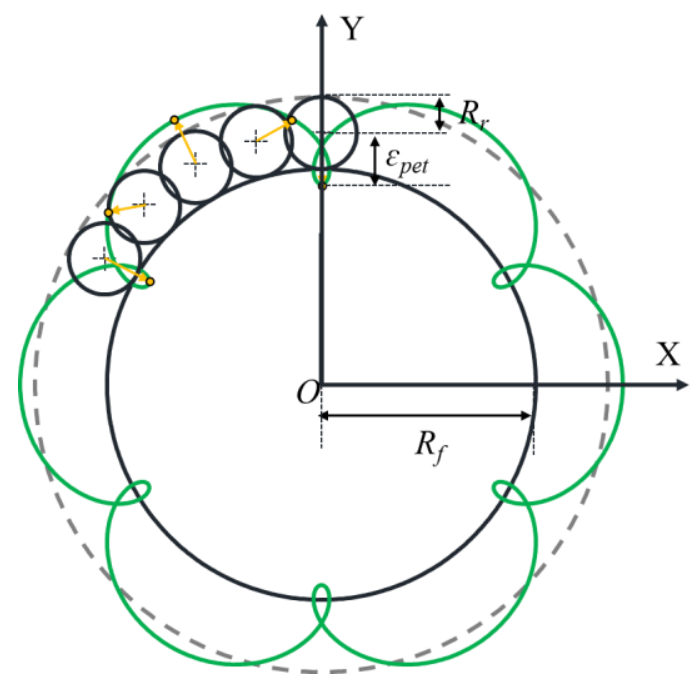

Figure 3. Prolate epitrochoid (PET) curve.

\subsubsection{Definition of $\delta q$}

$\delta q$ is an index for evaluating the various magnet shapes of surface permanent magnet synchronous motor (SPMSM). Figure 4 describes the rotor core to illustrate the definition of $\delta q . R_{\text {rotor }}$ is the radius of the rotor and $R_{\text {core }}$ is the radius of the rotor core. $\tau_{p}$ is the pole pitch and $\tau_{a}$ is the pole angle. The $\mathrm{d}$-axis is the axis in which the main magnetic flux is generated and is located in the center of the permanent magnet. In addition, the q-axis is an axis that is electrically opened at $90^{\circ}$ to the d-axis. $\delta q$ is the distance between the rotor radius and the intersection point where the cycloid curve meets the q-axis.

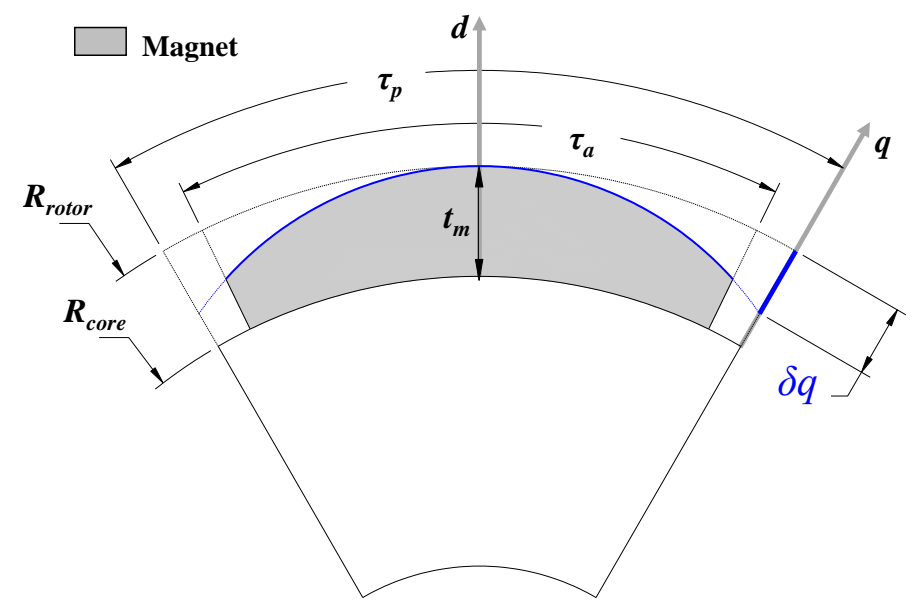

Figure 4. Definition of $\delta q$.

In order to define the shape profiles of CET and PET, the values of $R_{f}$ and $R_{r}$ in Equations 5 and 7 should be defined. In the case of CET, $R_{f}$ and $R_{r}$ are expressed by considering the geometrical relationship in terms of the known variables $\delta q, R_{\text {rotor }}$, and $n$ (the number of poles) (8) (10). In the case of PET, the values of $R_{f}$ and $R_{r}$ can be calculated by geometrical relationship [13].

$$
\begin{gathered}
\delta q=2 \varepsilon_{c e t} \\
R_{r}=\frac{2 R_{\text {rotor }}-\delta q}{2(n+1)}
\end{gathered}
$$




$$
R_{f}=\frac{n\left(2 R_{r}-\varepsilon_{c e t}\right)}{2(n+1)}
$$

\subsubsection{Curve Selection}

This study examines motor characteristics with the CET and PET. Considering the magnet thickness and rotor core radius, the epicycloid curve can draw only one curve, with $\delta q$ equal to the magnet thickness length. However, CET and PET have various magnet shapes according to $\delta q$, and the motor to which these curves are applied has various motor characteristics according to $\delta q$. Therefore, only the CET and PET are considered for the epicycloid curve to be applied to the rotor surface.

\subsection{Analysis Model}

This section presents the base model in which the cycloid curve is applied to the rotor shape according to $\delta q$. The epicycloid curve, which is a previously proposed curve, is a rotor surface design method. There also exists an eccentricity curve that is a commonly used rotor surface design method [13]. Therefore, the characteristics of the epicycloid curve were analyzed by comparing the motor performance after applying the eccentricity and epicycloid curves to the same motor.

\subsubsection{Base Model and Specification}

The motor type was surface permanent magnet synchronous motor (SPMSM), and the number of poles was six and the number of slots was nine. Figure 5 shows the rotor shape of two poles. Table 2 shows the main dimensions and magnetic material information of stator and rotor. The specifications of the magnet applying the proposed curve were thickness: $3 \mathrm{~mm}$, pole pitch: $60^{\circ}$, and angle: $52^{\circ}$ (Table 2).

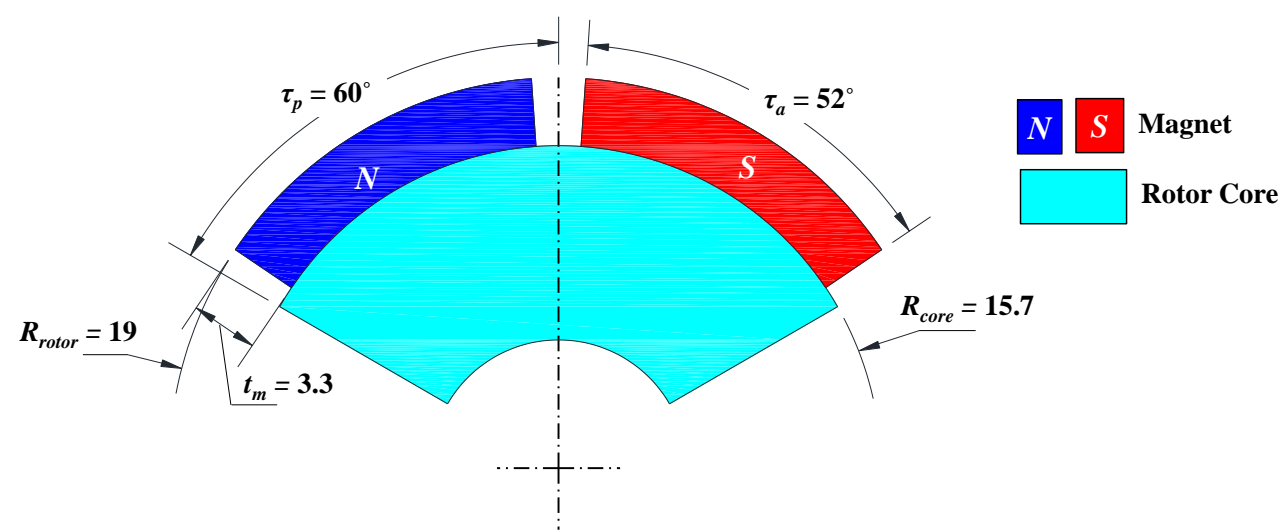

Figure 5. Base model.

Table 2. Design parameters of base model.

\begin{tabular}{cccccc}
\hline Classification & Unit & Value & Classification & Unit & Value \\
\hline Type & - & SPMSM & Rotor diameter & $\mathrm{mm}$ & 38 \\
\hline Phase/Pole/Slot & - & $3 / 6 / 9$ & Rotor length & $\mathrm{mm}$ & 57 \\
\hline Stator outer diameter & $\mathrm{mm}$ & 84 & Magnet thickness & $\mathrm{mm}$ & 3.3 \\
\hline Stator inner diameter & $\mathrm{mm}$ & 40 & Magnet $\mathrm{B}_{\mathrm{r}}$ & $\mathrm{T}$ & 1.297 \\
\hline Slot opening width & $\mathrm{mm}$ & 4 & Magnet $\mu_{\mathrm{r}}$ & - & 1.05 \\
\hline Slot opening depth & $\mathrm{mm}$ & 2 & Rated torque & $\mathrm{Nm}$ & 6 \\
\hline
\end{tabular}




\subsubsection{Magnet Shape Design}

Figure 6 shows the rotor model with epicycloid and eccentricity curves at $\delta q=3$, whereas Figure 7 shows the rotor model with epicycloid and eccentricity curves at $\delta q=4.5$. The rotor shape is divided into three colors: the rotor shape for the cycloid PET is blue, the rotor shape for the cycloid CET is green, and the rotor shape for the eccentricity is red. The curves for the CET and PET were applied to (5) and (7), respectively, to determine the rotor shape. In addition, the eccentricity curve was determined to satisfy the same $\delta q$. For $\delta q=3$ in Figure 6, a comparison of curve shapes indicates that different curves are generated at the same $\delta q$. However, in the case of $\delta q=4.5$ in Figure 7, a comparison of curve shapes indicates that the CET and PET curves are almost identical at the same $\delta q$.

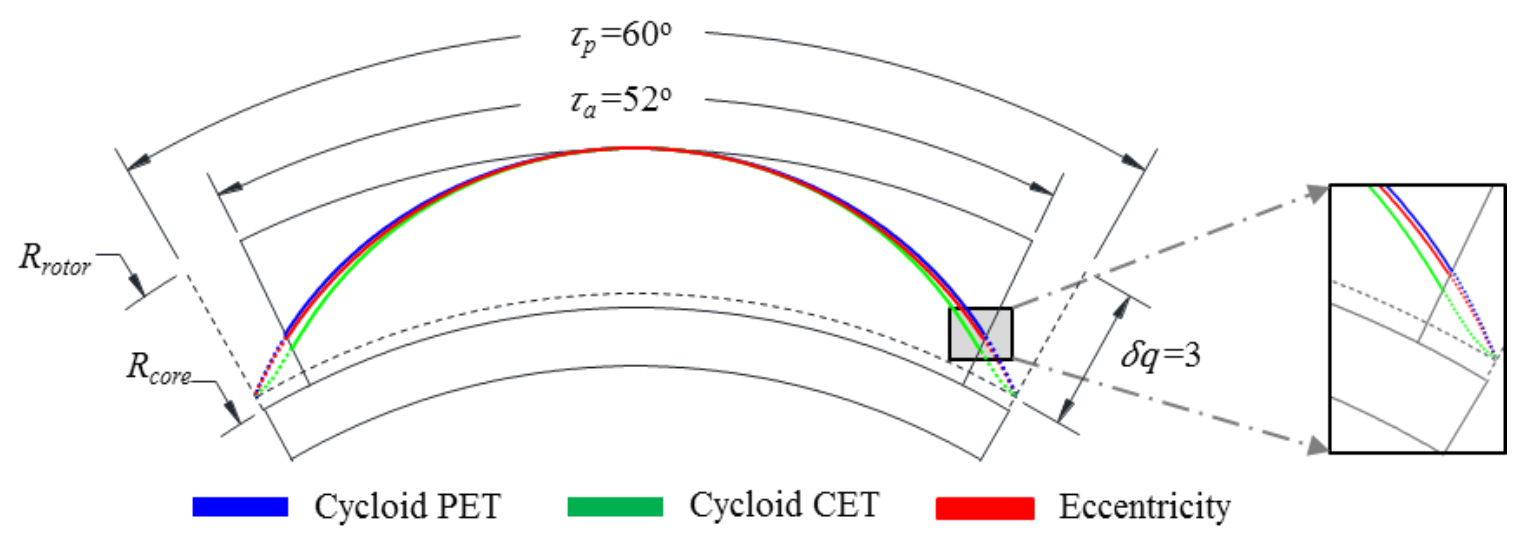

Figure 6. Magnet shape at $\delta q=3$ : CET, PET, and eccentricity.

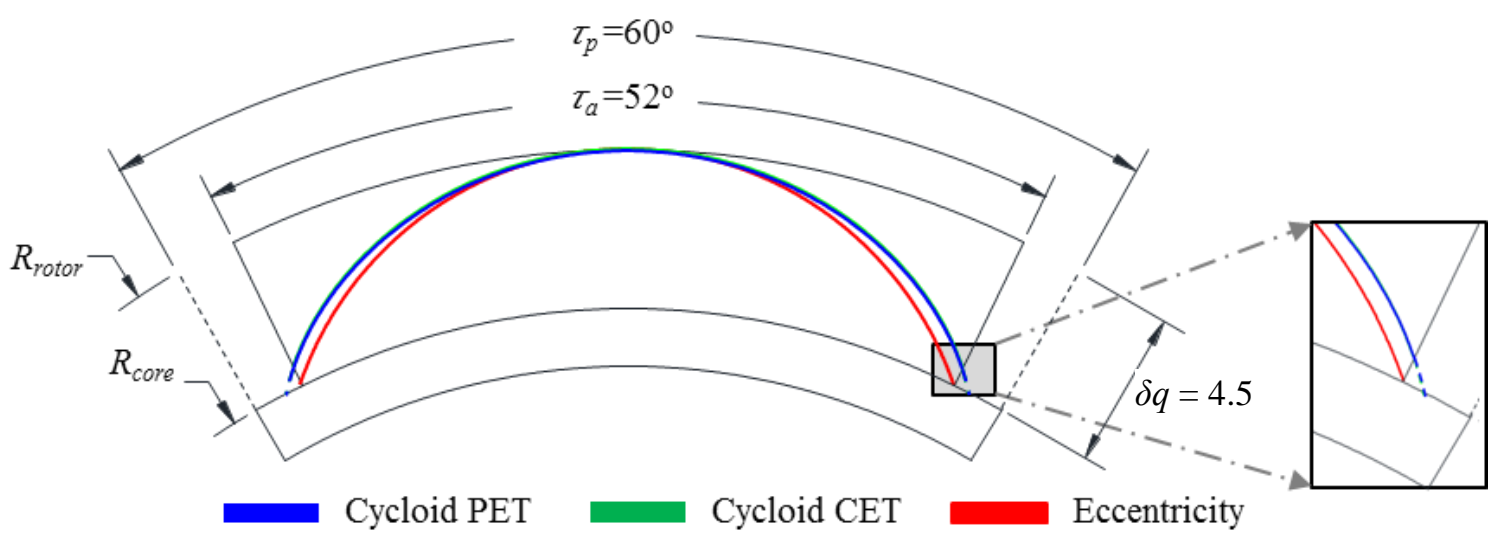

Figure 7. Magnet shape at $\delta q=4.5$ : CET, PET, and eccentricity.

\section{Performance Variation Analysis Due to Manufacturing Tolerance}

Tolerances inevitably occur during the manufacturing process. Manufacturing tolerances cause performance variations in a motor. Performance variation due to manufacturing tolerances is a major factor in determining the reliability of a product. There are two ways to increase the reliability of a product. The first is to better manufacture the product, and the second is to reduce tolerance-induced performance variation during the design process. This study considers the second method, and this section analyzes and evaluates the performance variation caused by manufacturing tolerances of the cycloid curve. The eccentricity curve is also analyzed and evaluated as a basis for comparison. Performance variation due to manufacturing tolerances is evaluated using the tolerance insensitivity rate (TIR). 


\subsection{Definition of TIR}

Typical manufacturing tolerances include the variation in magnetization direction, the magnet remnant flux density, the machining tolerances of components such as the stator and rotor shape, the assembly tolerances of components, and the property variation of magnetic material through manufacturing processes $[7,9,12]$. These are summarized in Table 3.

Table 3. Classification and causes of manufacturing tolerances in a motor.

\begin{tabular}{cc}
\hline Classification & Causes \\
\hline Magnet & $\begin{array}{c}\text { Errors due to magnetization method and condition } \\
\text {-Non-uniform magnetic direction and flux density }\end{array}$ \\
Geometry & $\begin{array}{c}\text { Poor management of a component's form tolerances due to manufacturing } \\
\text { method and condition }\end{array}$ \\
& -Stator/Rotor: stamping, wire-cutting \\
& -Magnet: sintering, grinding, coating, etc. \\
\hline Assembly & Poor management for assembling parts \\
& -Stator/Rotor: interlocking, welding, fitting \\
\hline Magnetic Characteristics & Deterioration of magnetic characteristics for electric core due to assembling \\
\hline
\end{tabular}

In this study, the TIR is used to express the degree to which manufacturing tolerances affect performance fluctuation through the use of the tolerance sensitivity evaluation method [16].

The TIR is given by

$$
\operatorname{TIR}=\frac{\Delta P}{\Delta T}
$$

where $\Delta T$ is the variation in manufacturing tolerances of the motor, such as the amount of $\Delta q$ variation of the cycloid or eccentricity curves and the magnet position of the rotor core assembly. $\Delta P$ refers to the performance variation of the motor according to $\Delta T$, such as variations in cogging torque, average torque, and torque ripple.

Herein, the target motor is for use in an EPS. The cogging torque of the EPS motor causes driver discomfort. Therefore, robustness of the cogging torque variation due to manufacturing tolerances is prioritized. Therefore, performance variation was analyzed in relation to cogging torque.

\subsection{Performance Variation for the Reference Model According to $\delta q$}

Here, we compare the tendency of the cogging torque according to $\delta q$ of the three curves. Figure 8 shows the cogging torque according to $\delta q$ for each curve applied to the motor. The value of cogging torque is the peak-to-peak value of 1 period.

As shown in Figure $8 \mathrm{a}$, the tendency of the cogging torque differs above and below $\delta q=1.5$. At $\delta q$ $<1.5$, the cogging torque decreases rapidly as $\delta q$ increases. At $1.5<\delta q<3$, the magnitude is similar to that at $\delta q=1.5$. At $\delta q>3$, the eccentricity curve increases the cogging torque greatly as $\delta q$ increases. However, both cycloid curves maintain similar values.

$$
\operatorname{TIR}_{\mathrm{CT}}=\frac{\Delta \text { CoggingTorque }_{p p}}{\Delta \delta_{q}}
$$

Figure $8 \mathrm{~b}, \mathrm{c}$ show the TIR of the cogging torque for $\Delta \delta q=1.5$ and $\Delta \delta q=3.25$, respectively. The TIR of the cogging torque is obtained from (9). At $\Delta \delta q=1.5$, the TIR of the cogging torque is a large negative value. Also, the magnitude of the TIR is similar for all curves. However, at $\Delta \delta q=3.25$, a different trend is observed (i.e., the cogging torque TIR of the eccentricity curve is largest). The cogging torque TIR of eccentricity is about four times that of PET and about six times that of CET. At $\Delta \delta q=$ 3.25 , the cycloid curve has a smaller performance variation of cogging torque than does the eccentricity 
curve owing to fabrication tolerances. Therefore, the analysis of the performance variation owing to manufacturing tolerances was performed at $\Delta \delta q=3.25$.

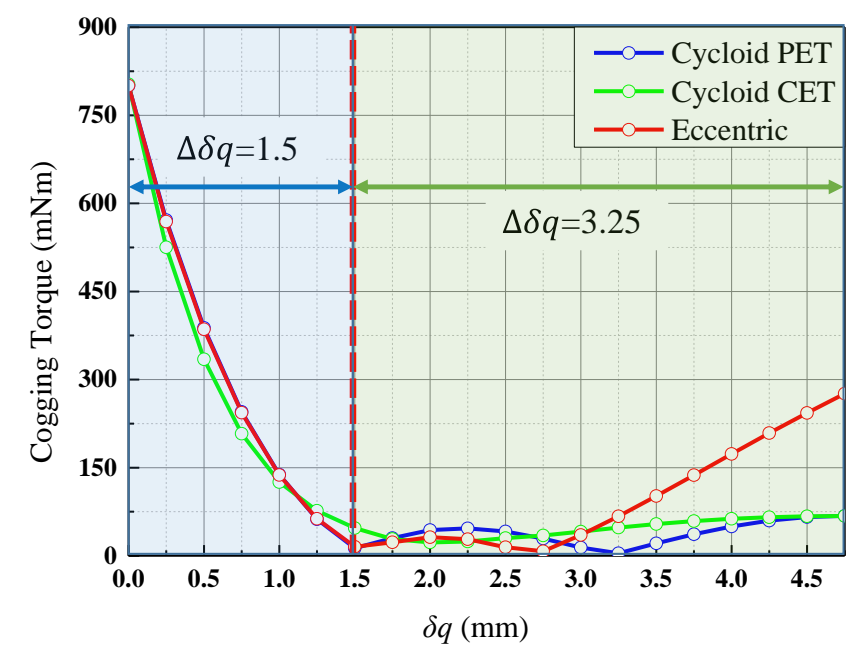

(a)

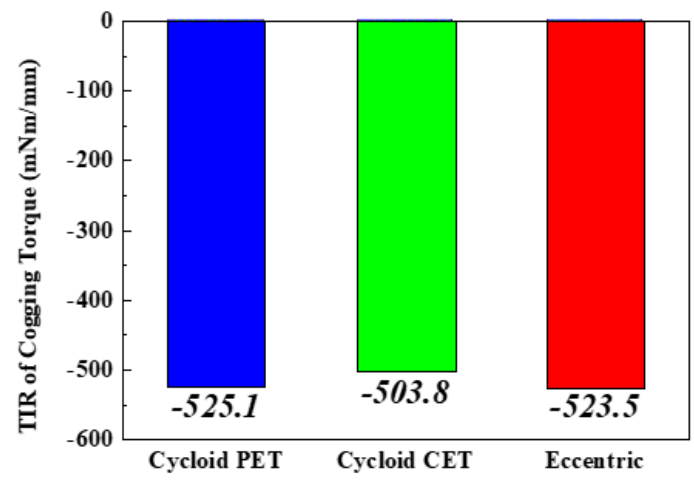

(b)

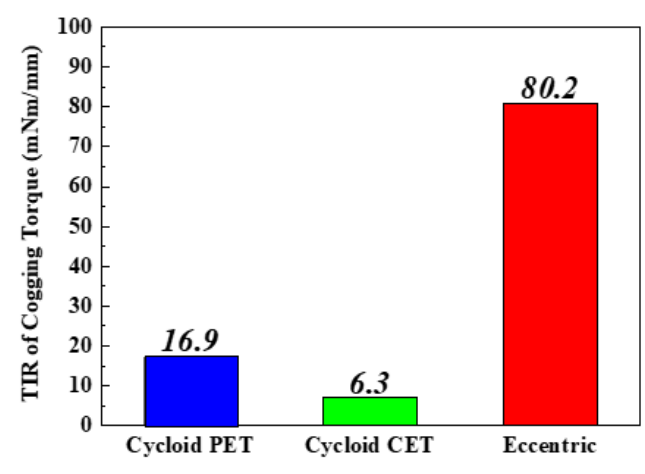

(c)

Figure 8. Cogging torque according to $\delta_{q}$ of each curve: (a) trend in cogging torque according to $\delta_{q}$;

(b) TIR of cogging torque (@ $\Delta \delta_{q}=1.5$ ); (c) TIR of cogging torque (@ $\Delta \delta_{q}=3.25$ ).

\subsection{Performance Varation for the Typical Manufacturing Tolerance Model According to $\delta q$}

In this section, we simultaneously analyze the performance variation of several manufacturing tolerances because the manufactured motor has various manufacturing tolerances. The analysis method is the same as that provided in Section 3.2. However, the target motor is a reference model with typical manufacturing tolerances, as shown in Figure 9. Figure 10 shows the cogging torque of models with typical manufacturing tolerances according to $\delta q$. 


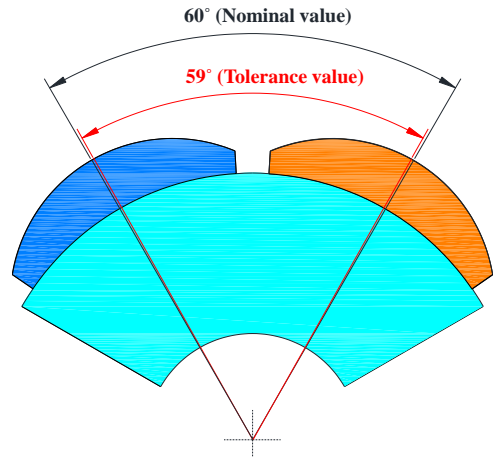

(a)

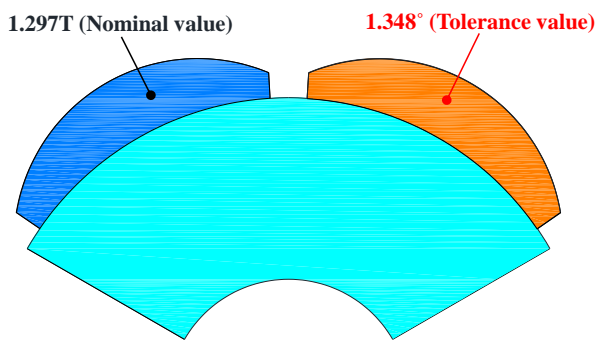

(b)

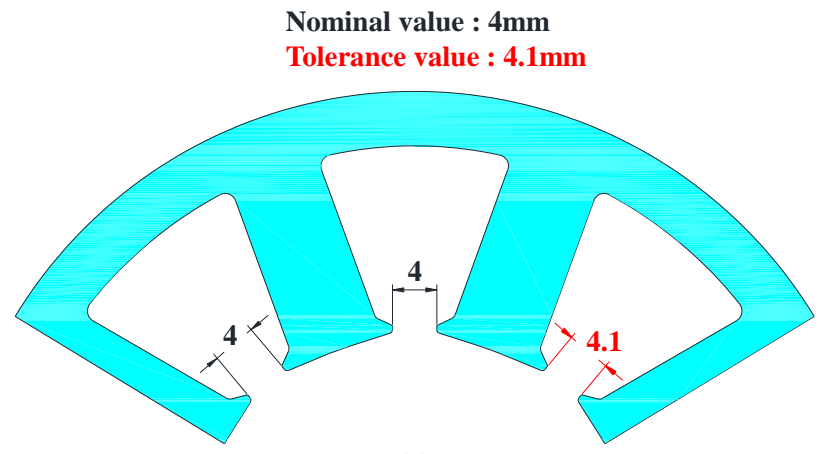

(c)

Figure 9. Typical manufacturing tolerance models of motors: (a) fabrication tolerance for position of permanent magnet; (b) fabrication tolerance for residual magnetic flux density of permanent magnet; (c) fabrication tolerance for the width of open slot.

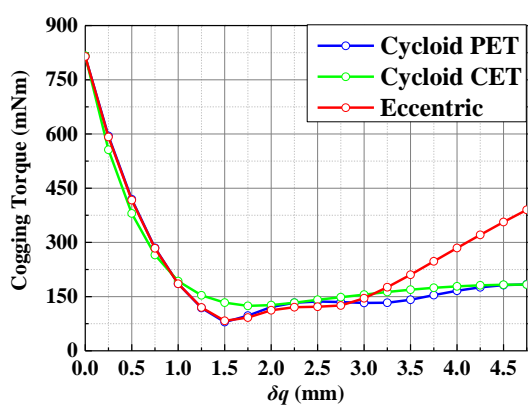

(a)

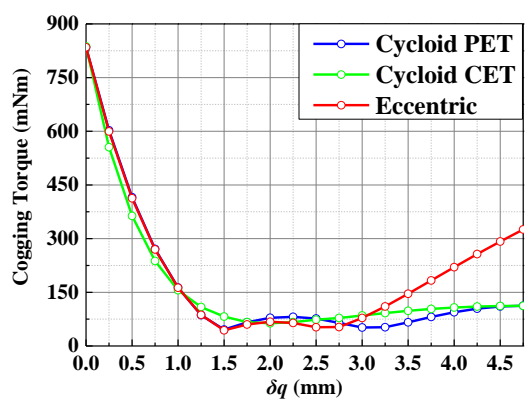

(b)

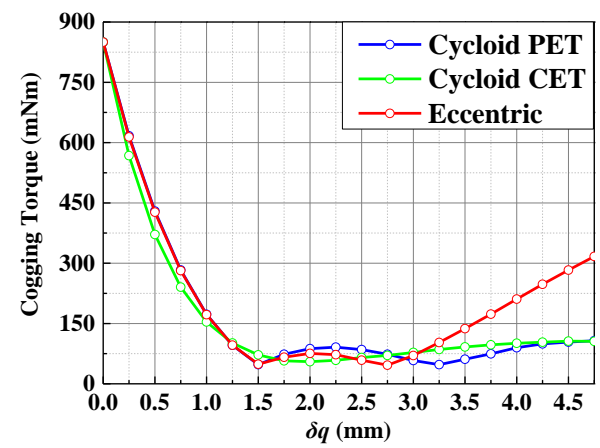

(c)

Figure 10. Cogging torque according to $\delta q$ of each curve for a typical manufacturing tolerance model: (a) fabrication tolerance for position of permanent magnet; (b) fabrication tolerance for residual magnetic flux density of permanent magnet; (c) fabrication tolerance for width of open slot. 
Figure 11 shows the TIR of the cogging torque for the model with typical manufacturing tolerances at $\Delta \delta q=3.25$. For the three models, the trend in the cogging torque according to $\delta q$ is similar to that of the previous analysis. Moreover, at $\Delta \delta q=3.25$, the TIR of the cogging torque is similar to that of the previous analysis. As a result, it is considered that the cycloid curve is more advantageous in relation to manufacturing tolerances than is the eccentricity curve.

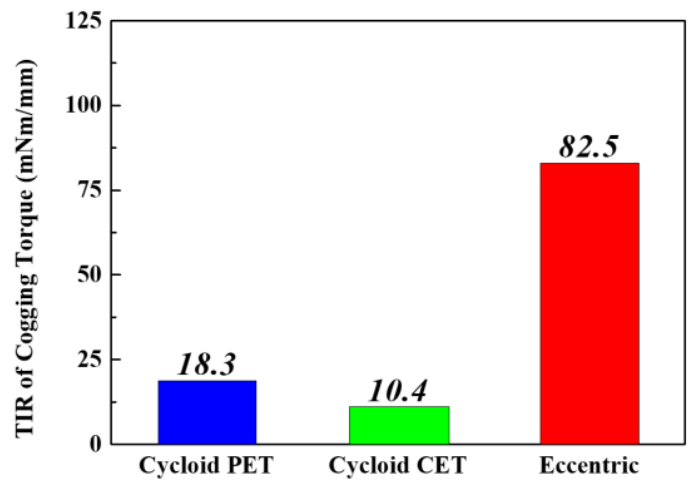

(a)

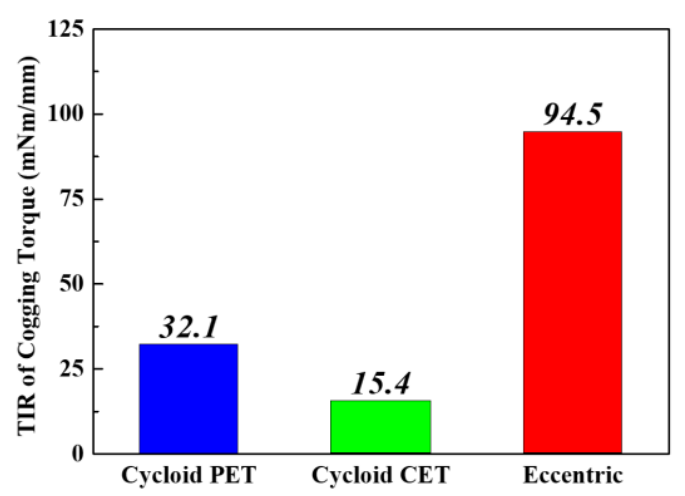

(b)

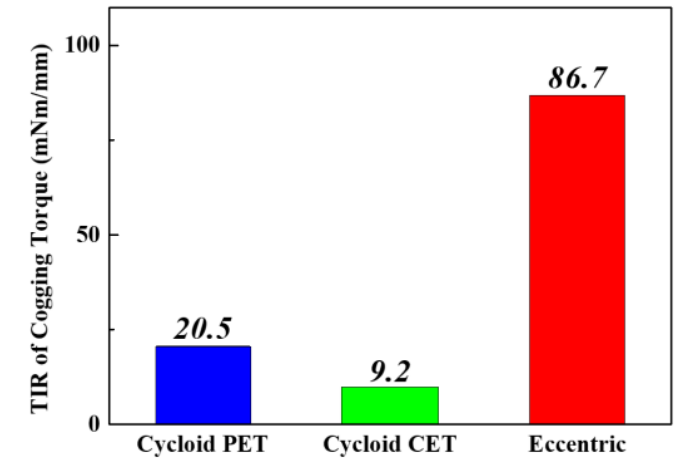

(c)

Figure 11. TIR of cogging torque (@ $\Delta \delta q=3.25$ ): (a) fabrication tolerance for position of permanent magnet; (b) fabrication tolerance for residual magnetic flux density of permanent magnet; (c) fabrication tolerance for width of open slot.

\section{Experiment}

\subsection{Prototype}

The fabricated motors were tested to verify the analysis of performance variation according to the tolerances of the cycloid and eccentric curves. When $\delta q=4.5 \mathrm{~mm}$, the electrical performances of PET and CET are not different because the shapes of the two cycloid curves PET and CET are almost the same. Therefore, two rotors were manufactured by applying the same $\delta q$ of the cycloid and the eccentric curves (i.e., $4.5 \mathrm{~mm}$ ). Table 4 shows the magnet and rotor shapes manufactured by applying cycloid and eccentric curves. 
Table 4. Prototype: magnet and rotor assembly.

\begin{tabular}{cccc}
\hline Prototype & Cycloid & Eccentric \\
\hline Magnet & & & \\
Rotor Assembly & 0 & 1 & \\
\hline
\end{tabular}

Figure 12 shows the 3D tester instrument used to scan and evaluate the fabricated magnet surface. Figure 13 shows the scan results for the fabricated magnets. The scan results are represented by red dots and diagrams of the magnet are represented as black lines. Table 5 shows the error between the scan results and the diagrams. The fabricated cycloid magnets had a maximum error of $0.06 \mathrm{~mm}$ and a minimum of $0.01 \mathrm{~mm}$. The fabricated eccentric magnets had a maximum error of $0.09 \mathrm{~mm}$ and a minimum of $0.06 \mathrm{~mm}$. As a result, it can be seen that each magnet was successfully fabricated when applying the two curves. However, rotor tolerances may occur during the manufacturing process of the rotor core or during the magnet assembly process.

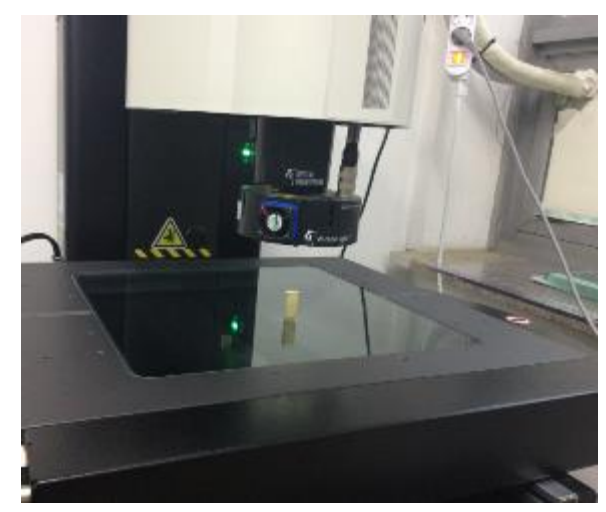

Figure 12. Measurement of manufactured magnet.

Table 5. Measured errors.

\begin{tabular}{ccccc}
\hline \multicolumn{2}{c}{ Prototype } & Unit & Cycloid & Eccentric \\
\hline \multirow{2}{*}{$\begin{array}{c}\text { Measured errors } \\
(\mathbf{m m})\end{array}$} & Maximum & $\mathrm{mm}$ & 0.06 & 0.09 \\
\cline { 2 - 5 } & Minimum & $\mathrm{mm}$ & -0.01 & -0.06 \\
\hline
\end{tabular}




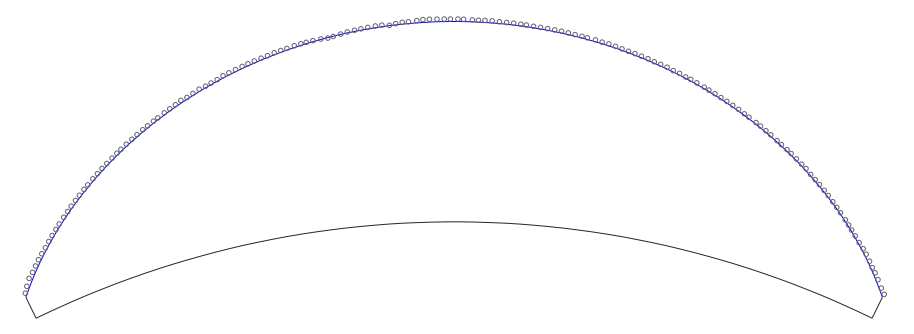

(a)

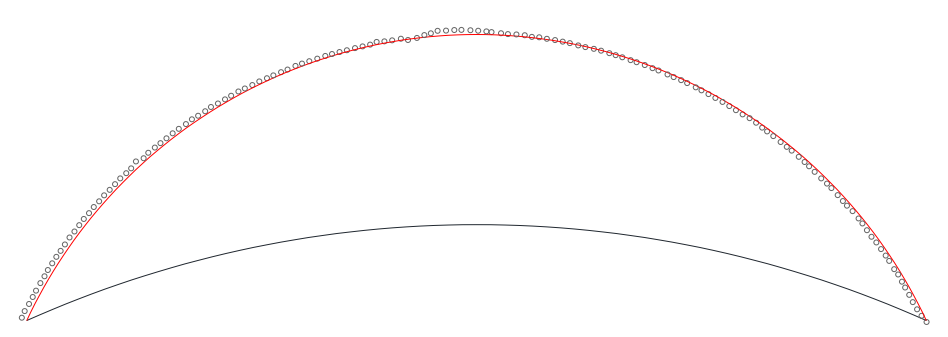

(b)

\section{- Cycloid Curve \\ $\bigcirc \quad$ Measured Data}

Figure 13. Measured shape of magnet: (a) cycloid; (b) eccentric.

\subsection{Cogging Torque Test}

Figure 14 shows the cogging torque test for the cycloid and eccentric curves. For both models, cogging torque was measured using the same instrument. Cogging torque was measured according to rotor position. The measurement speed was $1 \mathrm{rpm}$ and the measurement temperature was $25^{\circ} \mathrm{C}$.
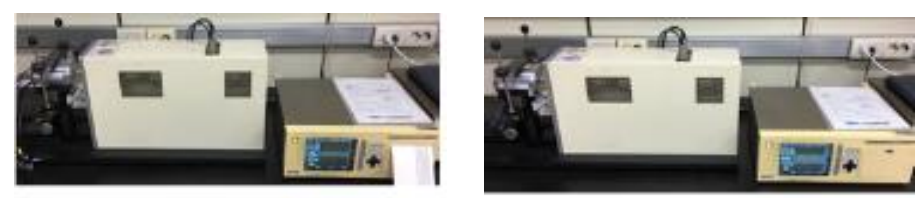

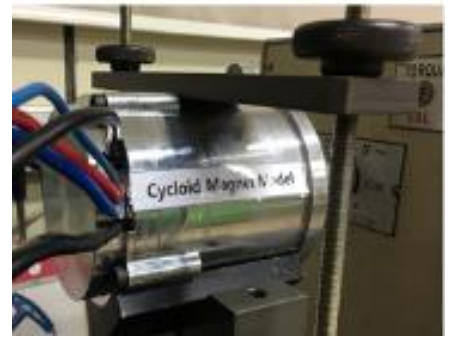

(a)

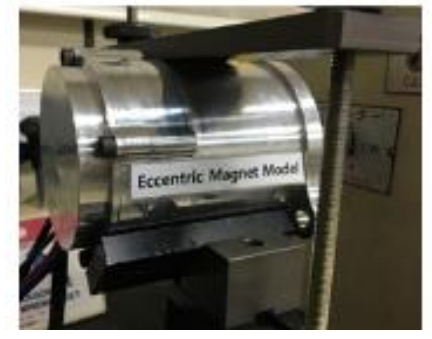

(b)

Figure 14. Cogging torque test for prototype: (a) cycloid; (b) eccentric.

Figure 15 presents the finite element analysis (FEA) and test results for the cycloid and eccentric curves. The test results show the 18 periods of cogging torque wave form. The cogging torque amplitude was larger for the eccentric curve than for the cycloid curve. The cogging torque periodicity was of the 18th harmonic order, which is the least common multiple of the number of poles and slots. 


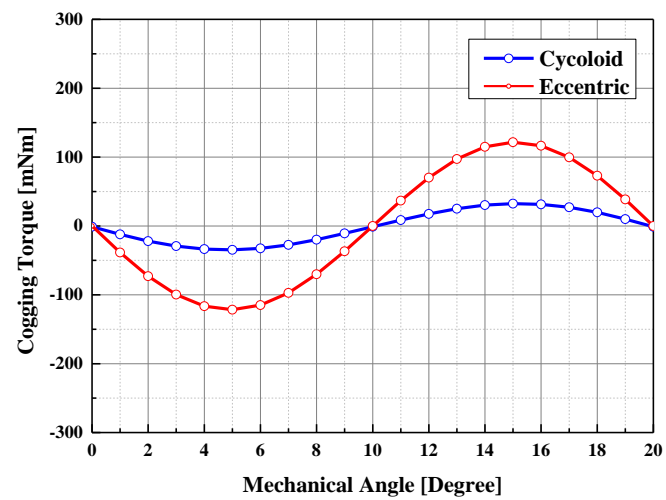

(a) FEA

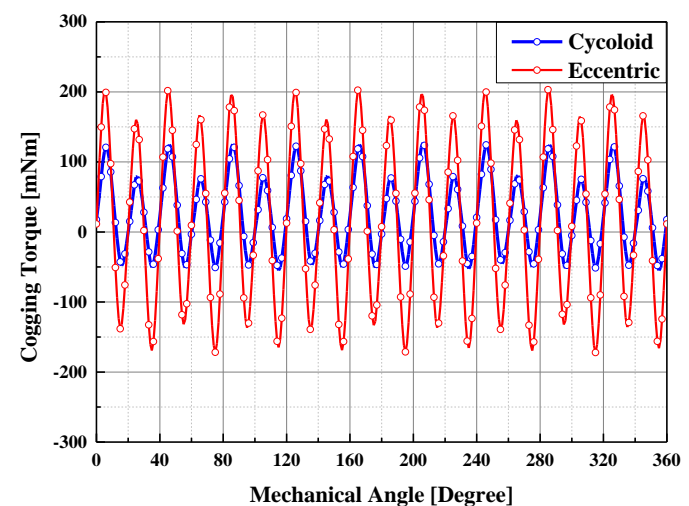

(b) Test

Figure 15. Cogging torque FEA and test results: (a) FEA; (b) test.

Table 6 shows the cogging torque magnitudes for the FEA and test results. When comparing the FEA results with the test results, the cogging torque of the test results was greater than that of the FEA. As many previous papers have suggested, manufacturing tolerances can increase the cogging torque of the test results rather than the cogging torque of the FEA [14,17]. However, it was confirmed that the cogging torque was smaller when applying the cycloid curve than when applying the eccentric curve.

Table 6. Cogging torque for FEA and test results considering rotor tolerance.

\begin{tabular}{cccc}
\hline Prototype & Unit & Cycloid (peak-to-peak) & Eccentric (peak-to-peak) \\
\hline FEA & $\mathrm{mNm}$ & 67 & 243 \\
\hline Test & $\mathrm{mNm}$ & 182 & 375 \\
\hline
\end{tabular}

The back-EMF was also analyzed to compare the performance of cycloid and eccentric model. Figure 16 shows the wave form of back-EMF (phase) and harmonic order for the cycloid and eccentric models with $\delta q=4.5$; the magnitudes of fundamental order for the cycloid and eccentric models were 3.03 and $2.84 \mathrm{~V}$, respectively.

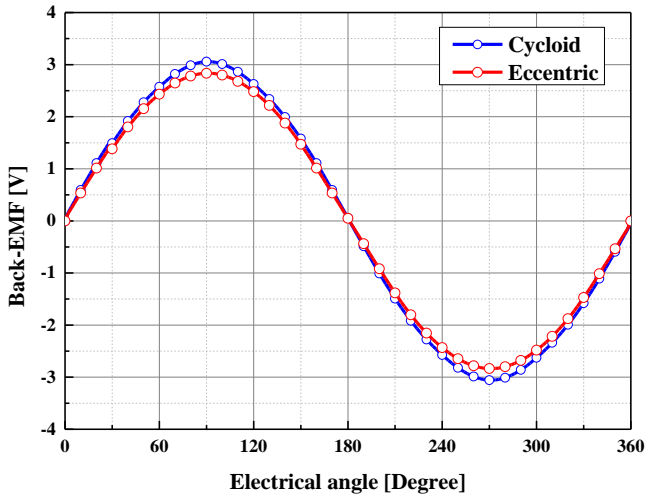

(a) Waveform

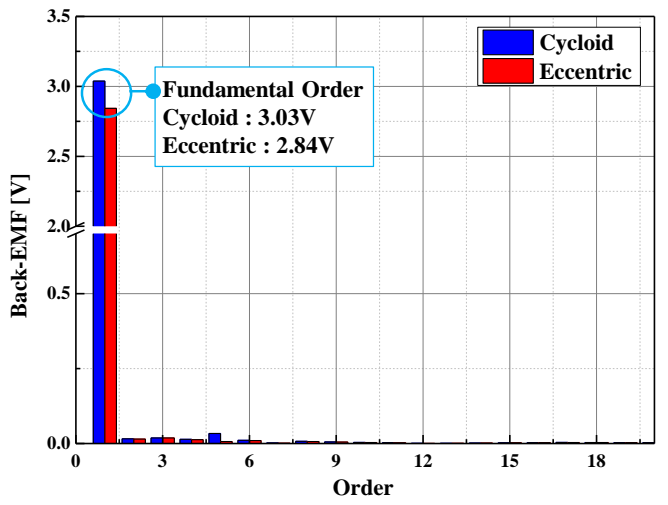

(b) Harmonic order

Figure 16. Back-EMF: (a) waveform; (b) harmonic order.

Table 7 and Figure 17 show the comparison of magnet volume, back-EMF, and cogging torque. In Table 7, the volume of magnet was that of one pole. The change rate means the increase or decrease percentage of the cycloid model compared to the eccentric model. In the cycloid model, the magnitude 
of back-EMF increased by $5.4 \%$ as the magnet volume increased. However, the cogging torque was sharply reduced to $72 \%$.

Table 7. Magnet volume, back-EMF, and cogging torque for FEA results.

\begin{tabular}{ccccc}
\hline Item & Unit & Cycloid & Eccentric & Change Rate \\
\hline Magnet volume & $\mathrm{mm}^{3}$ & 2115 & 1962 & $7.8 \%$ increased \\
\hline Back-EMF & $\mathrm{V}$ & 3.03 & 2.84 & $6.7 \%$ increased \\
\hline Cogging torque & $\mathrm{mNm}$ & 67 & 243 & $72 \%$ decreased \\
\hline
\end{tabular}

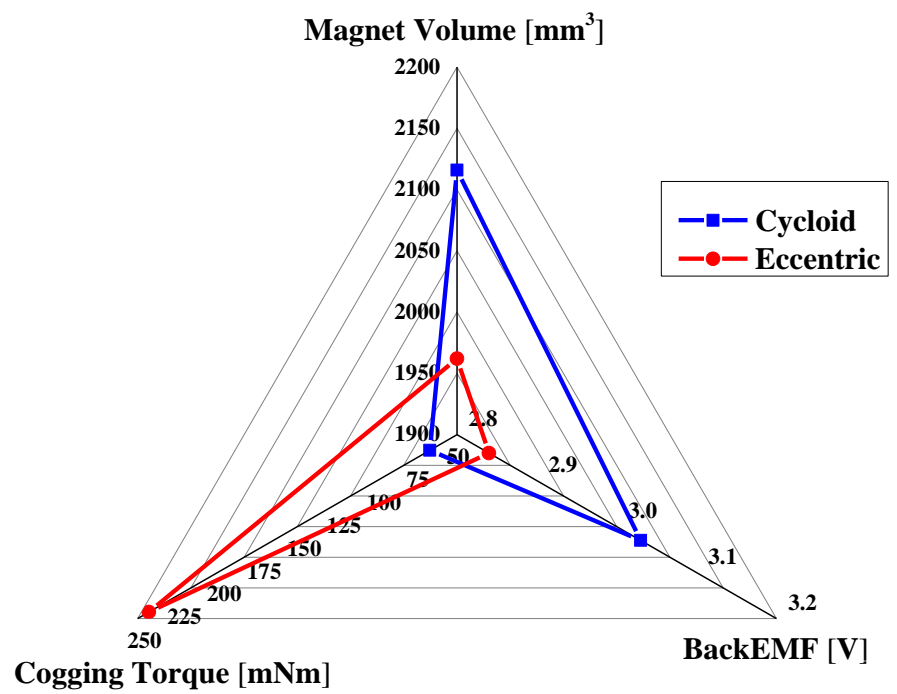

Figure 17. Comparison of magnet volume, back-EMF, and cogging torque for FEA results.

\section{Conclusions}

This work analyzed the tolerance sensitivity of cycloid and eccentric curves. First, $\delta q$ was defined to compare the performance of a motor applied with cycloid and eccentric curves under the same conditions. The change in $\delta q$ of each curve was defined as a tolerance. The effect on tolerances was analyzed using TIR. Next, the effects of tolerances were examined by applying cycloid and eccentric curves to the reference model and typical manufacturing tolerance models. At $\Delta \delta q=1.5 \mathrm{~mm}$, the TIRs for the three curves showed similar values, whereas at $\Delta \delta q=3.25 \mathrm{~mm}$, the cycloid curve was more robust in relation to tolerances than was the eccentricity curve. Finally, to verify the validity of the work, motors with cycloid and eccentric curves were fabricated and tested. Both motors generated additional cogging torque due to the tolerances of the rotor. To undertake a comparison under the same conditions, FEA was performed. This confirmed that the FEA results reflected the tolerances of the rotor, with the test results showing the same. In the case of the prototype's back-EMF with $\delta q=4.5$ $\mathrm{mm}$, the magnitude of back-EMF increased by $6.7 \%$ as the magnet volume increased. However, the cogging torque, which is the key factor to improve the noise vibration harshness $(\mathrm{NVH})$ characteristics of the EPS system, was sharply reduced to $72 \%$. Therefore, the cycloid curve is considered more robust in relation to tolerances than is the eccentric curve.

Author Contributions: Conceptualization, C.-S.L.; validation, K.-S.C.; data curation, J.-C.P.; writing-original draft preparation, C.-S.L.; supervision, M.-S.I. All authors have read and agreed to the published version of the manuscript.

Funding: This work was funded by the National Research Foundation of Korea (NRF) and the Korea government (MSIP; Ministry of Science, ICT \& Future Planning), grant number 2018R1C1B5085447.

Conflicts of Interest: The authors declare no conflict of interest. 


\section{References}

1. Quak, H.; Nesterova, N.; Rooijen, T.V.; Dong, Y. Zero emission city logistics: Current practices in freight electromobility and feasibility in the near future. Transp. Res. Procedia. Appl. 2016, 14, 1506-1515. [CrossRef]

2. Levin, N.; Orlova, S.; Pugachov, S.; Ose-Zala, B.; Jakobsons, E. Methods to reduce cogging torque in permanent magnet synchronous machines. Elektronika IR elektrotechnika. 2013, 19, 23-26. [CrossRef]

3. Park, Y.U.; Cho, J.H.; Kim, D.K. Cogging torque reduction of single-phase brushless DC motor with a tapered air-gap using optimizing notch size and position. IEEE Trans. In. Appl. 2015, 51, 4455-4463. [CrossRef]

4. Wanjiku, J.; Khan, M.A.; Barendse, P.S.; Pilay, P. Influence of slot openings and tooth profile on cogging torque in axial-flux pm machines. IEEE Trans. Ind. Electron. 2015, 62, 7578-7589. [CrossRef]

5. Hwang, M.; Lee, H.; Cha, H. Analysis of torque ripple and cogging torque reduction in electric vehicle traction platform applying rotor notched design. Energies 2018, 10, 3053. [CrossRef]

6. Blum, J.; Merwerth, J.; Herzog, H.G. Investigation of the Segment Order in Step-Skewed Synchronous Machines on Noise and Vibration. In Proceedings of the International Electric Drives Production Conference (EDPC), Nuremberg, Germany, 30 September-1 October 2014; pp. 1-6.

7. Fei, W.; Luk, P.C.K.; Shen, J. Torque analysis of permanent-magnet flux switching machines with rotor step skewing. IEEE Trans. Magn. 2012, 48, 2664-2673. [CrossRef]

8. Jung, Y.H.; Lim, M.S.; Yoon, M.H.; Jeong, J.S.; Hong, J.P. Torque ripple reduction of IPMSM applying asymmetric rotor shape under certain load condition. IEEE Trans. Energy Conversion 2018, 33, 333-340. [CrossRef]

9. Kim, J.M.; Yoon, M.H.; Hong, J.P.; Kim, S.I. Analysis of cogging torque caused by manufacturing tolerances of surface-mounted permanent magnet synchronous motor for electric power steering. IEEE Trans. Electr. Power Appl. 2016, 10, 1691-1696. [CrossRef]

10. Coenen, I.; Giet, V.D.; Hameyer, K. Manufacturing tolerances: estimation and prediction of cogging torque influenced by magnetization faults. IEEE Trans. Magn. 2012, 48, 1932-1936. [CrossRef]

11. Jonathon, W.S. Unified approach to cycloid curve, profile, stress and efficiency optimization. J. Mech. Des. 2010, 132, 667-673.

12. Colbourne, J.R. The geometry of trochoid envelopes and their application in rotory pumps. Mech. Mach. Theory 1974, 9, 421-435. [CrossRef]

13. Park, H.J.; Lim, M.S.; Lee, C.S. Magnet shape design and verification for SPMSM of EPS system using cycloid curve. IEEE Access 2019, 7, 137207-137216. [CrossRef]

14. Ou, J.; Liu, Y.; Qu, R.; Doppelbauer, M. Experimental and theoretical research on cogging torque of PM synchronous motors considering manufacturing tolerances. IEEE Trans. Ind. Electron. 2018, 66, 3772-3783. [CrossRef]

15. Coenen, M.; Van der, G.; Hameyer, K. Manufacturing tolerances: Estimation and prediction of cogging torque influenced by magnetization. IEEE Trans. Magn. 2012, 48, 2664-2673. [CrossRef]

16. Joskowicsz, L.; Sacks, E. Kinematic tolerance analysis. Comput. Aided. Des. 1997, 29, 147-157. [CrossRef]

17. Lovrenc, G.; Andrej, C.; Stojan, M.; Rastko, F. Additional cogging torque components in permanent-magnet motors due to manufacturing imperfections. IEEE Trans. Magn. 2009, 45, 1210-1213.

(C) 2020 by the authors. Licensee MDPI, Basel, Switzerland. This article is an open access article distributed under the terms and conditions of the Creative Commons Attribution (CC BY) license (http://creativecommons.org/licenses/by/4.0/). 